\title{
Pre-clerkship students' perception and learning behavior of online classes during coronavirus disease 2019 pandemic
}

\author{
Ye Ji Kang and Do-Hwan Kim
}

Department of Medical Education, Hanyang University College of Medicine, Seoul, Korea

Purpose: This study aims to analyze pre-clerkship medical students' learning strategies and perceptions in online classes during the coronavirus disease 2019 pandemic.

Methods: To develop the survey items, 20 pre-clerkship students were interviewed about their learning experiences in the first semester of 2020. A total of 425 pre-clerkship students have participated in the survey, which comprised four parts (general experience, learning strategies, important features, and overall satisfaction).

Results: Before classes began, students generally had "neutral expectations" about online classes (2.90 out of 5). At the end of the semester, overall satisfaction with the curriculum was moderate (3.04 out of 5). Premedical students reported lower scores in "daily study hours" and "regular lifestyle" and higher scores in "experience of playing recorded lectures solely for an attendance check" ( $p<0.001)$. In addition, first-year premedical students not only showed significantly lower utilization of learning strategies compared to other grades $(p<0.001)$.

Conclusion: Although pre-clerkship students mostly shared similar perceptions and behaviors in their learning regardless of grade level, some characteristics were either more prominent in premedical students on the whole or limited to first-year premedical students.

Key Words: COVID-19, Online education, Online learning, Undergraduate medical education, Pre-clerkship students

\section{Introduction}

The coronavirus disease 2019 (COVID-19) pandemic caused sweeping changes in political, economic, and social aspects worldwide-and education was no exception. Particularly, the pandemic has "forced" classes to be non-contact based online lectures. Unlike the past, the professors are no longer able to "choose" between contact and non-contact methods based on their learning objectives and the type of educational content. Previous studies have reported that students prefer online classes mostly because they are liberated from restrictions in time and space and save time moving between classrooms [1]. However, in the absence of other options, learning at home can be an isolating experience, and, as it has been pointed out, COVID-19 has affected the mental health of college students across various dimensions [2].

Although some reviews reported that synchronous
Received: March 8, $2021 \bullet$ Revised: April 14, $2021 \bullet$ Accepted: May 4, 2021 Corresponding Author: Do-Hwan Kim (https://orcid.org/0000-0003-4137-7130) Department of Medical Education, Hanyang University College of Medicine, 222-1 Wangsimni-ro, Seongdong-gu, Seoul 04763, Korea

Tel: +82.2.2220.0693 email: mededkimdh@hanyang.ac.kr
Korean J Med Educ 2021 Jun; 33(2): 125-131

https://doi.org/10.3946/kjme.2021.194

eISSN: 2005-7288

(C) The Korean Society of Medical Education. All rights reserved. This is an open-access article distributed under the terms of the Creative Commons Attribution Non-Commercial License (http:// creativecommons.org/licenses/by-nc/3.0/), which permits unrestricted non-commercial use, distribution, and reproduction in any medium, provided the original work is properly cited. 
distance education is associated with higher satisfaction than traditional education [3], current evidence is not enough to conclude that curriculums conducted fully online would yield similar results. Moreover, previous studies reported during COVID-19 focus on the clinical workplace or clerkship phases of the undergraduate medical education program $[4,5]$. However, changes in the pre-clerkship curriculum cannot be overlooked, since premedical and preclinical education serve as the foundation for the later stages of medical school education. To improve online classes that are most likely to continue after the pandemic, it is crucial to understand students' responses to educational changes brought on by COVID-19.

Therefore, this study aims to analyze the learning behavior and perception of online classes among students in the pre-clerkship phase who participated in full-scale online classes conducted during COVID-19.

\section{Methods}

\section{Setting}

In February 2020, in response to the spread of COVID-19, Hanyang University College of Medicine (HYUCM) switched all its lecture-oriented courses to an online platform (Blackboard). All online classes were subsequently delivered through this platform. Professors were able to choose between live-synchronous and recorded-asynchronous methods, according to their preferences.

\section{Development of the survey}

First, focus group interviews were conducted for 20 pre-clerkship students to develop survey questions. In the semi-structured interview, students were asked about experiences and thoughts on the "online learning environment", "changes in learning strategies after the online classes", and "the situation changed to online classes". The collected data were transcribed, coded, and analyzed, resulting in two main themes: perception of online classes and characteristics of learning behavior in online classes. The final survey questions were developed after pilot tests for groups of medical education experts and students. The survey consisted of the following parts: general experiences, learning strategies, important features, perception of the professors and changes in interactions, and overall satisfaction. The items were measured on a 5- or 6-point Likert scale, depending on the specifics.

\section{Data collection and analysis}

The survey was conducted from June to July 2020 on students across four grades from premedical course (PM1 and PM2) to medical student (M1 and M2). For each item, we analyzed differences between the four grades of students using one-way analysis of variance. When statistically significant differences existed, we used Tukey's honestly significant difference test for the post-hoc comparison and calculated eta squared as measures of the effect sizes. For all statistical analyses, IBM SPSS Statistics for Windows ver. 26.0 (IBM Corp., Armonk, USA) was used.

\section{Ethics statement}

This study was approved by the Institutional Review Board (IRB) of Hanyang University (approval no., HYU-2020-081). The IRB of Hanyang University waived the need for explicit consent from participants. 


\section{Results}

\section{Demographic characteristics}

A total of 425 students from four grades responded to the survey, an overall response rate of $96.2 \%$. The average age of the respondents was 20.8 years, and $73.7 \%$ were male. There was no statistically significant difference in gender $(\mathrm{p}=0.648)$ or grade point average (GPA) when compared to the previous semester $(p=0.637)$ between the grades.

\section{General experiences of online classes}

On average, the utilization of online classes during the period of secondary education before entering medical school was low (2.68 out of 5). Moreover, $32.7 \%$ of the students responded that they had "hardly used" online classes, which resulted in a bimodal distribution pattern. "Expectations for online classes before the start of the semester" were mostly negative for PM1. Premedical students had significantly fewer "daily study hours" $(\mathrm{p}<0.001)$ and less "regular lifestyle" $(\mathrm{p}<0.001)$ when compared with M1 and M2 students, and their "experience of playing recorded lectures solely for attendance check" was significantly higher $(p<0.001)$ (Table 1).

\section{Learning strategies}

The learning strategies most frequently used by medical students was "pausing for the purpose of learning" (4.12 out of 5), followed by "increasing playback speed" (3.82 out of 5) (Table 2). "Watching while taking notes", "pausing for the purpose of refreshment", and "repeated viewing of specific sections" were also strategies respondents used in more than half of the lectures. The numbers of students who studied

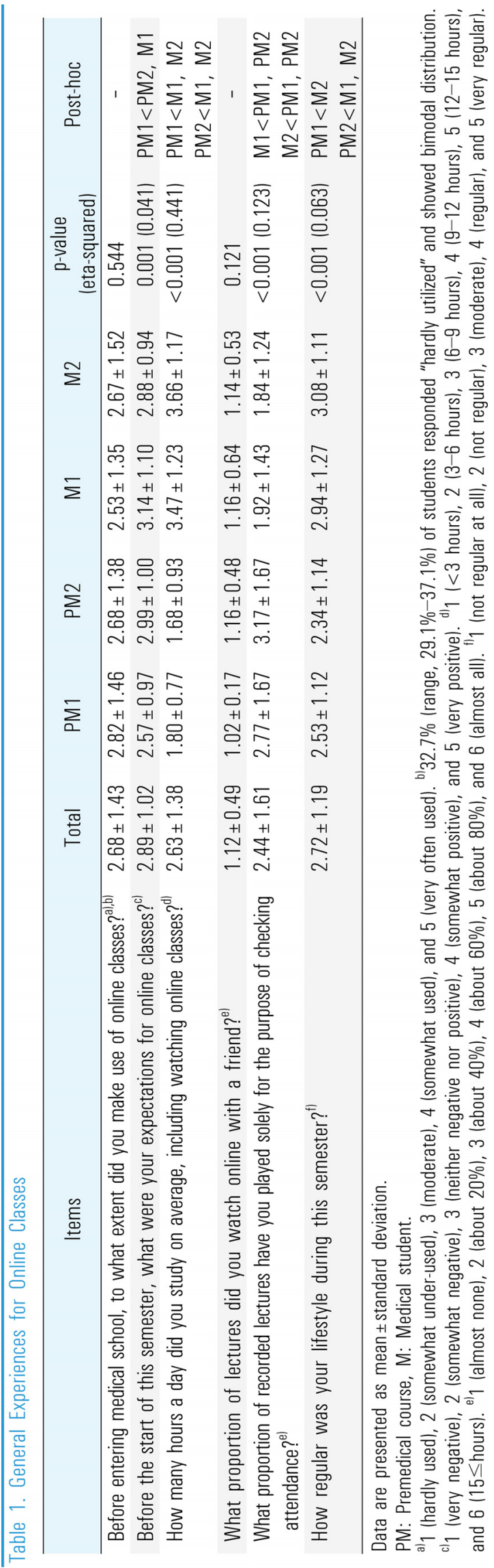




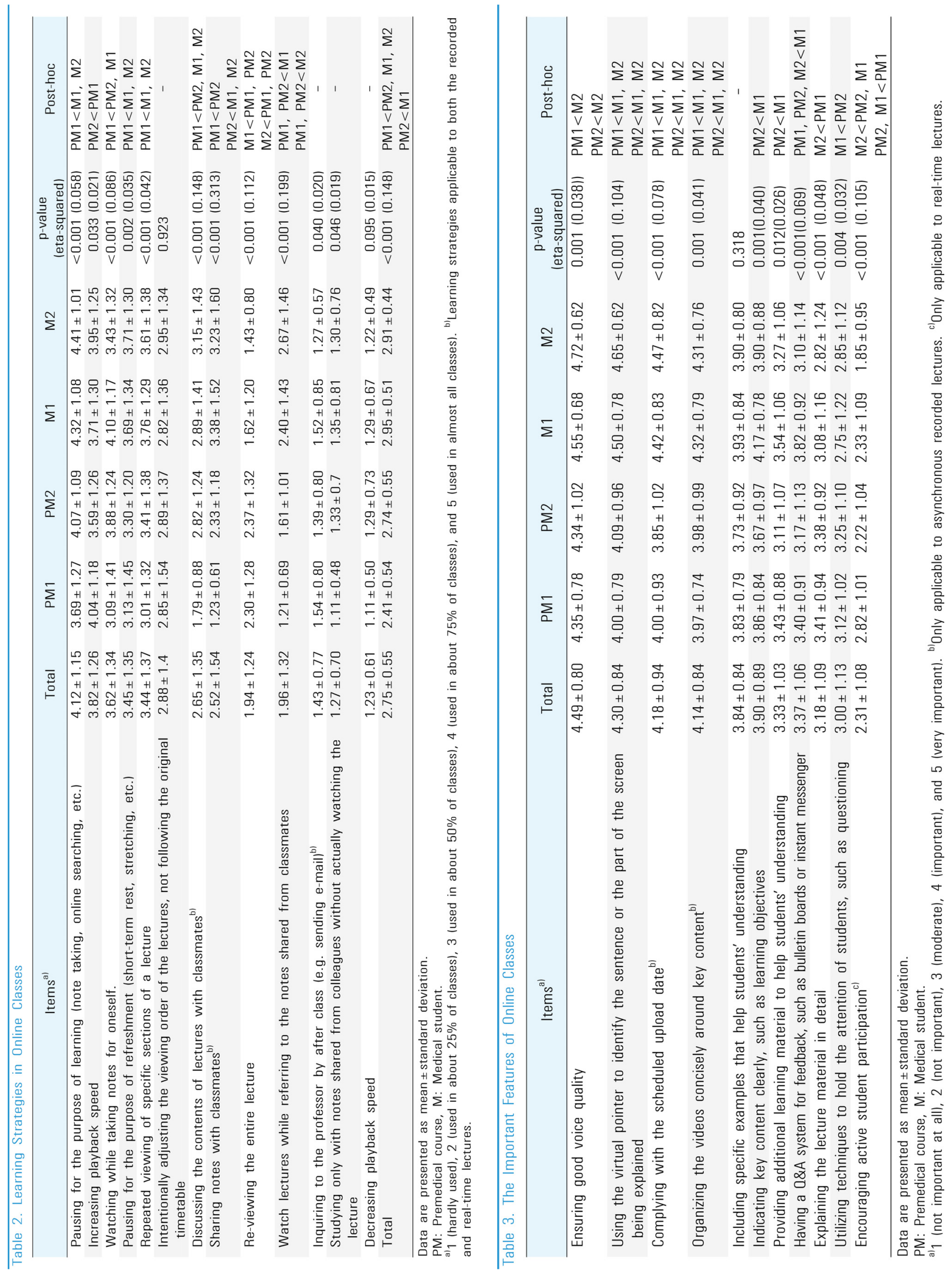


without watching lectures or watched with decreased playback speed were few. PM1 students showed significantly lower utilization than students in the other three grades $(\mathrm{p}<0.001)$.

\section{Important features of online classes}

Regarding the various elements of online classes (Table 3), "good voice quality," "using the virtual pointer," "complying with the scheduled upload date," and "organizing the videos concisely" received higher than 4 points, indicating that they were seen as important by the students. Although "encouraging active student participation" during real-time lectures was valued as the least important feature (2.31 out of 5) overall, PM1 valued this significantly higher than students in the other three grades $(p<0.001)$.

\section{Overall satisfaction}

Overall satisfaction with the curriculum was moderate (3.04 out of 5), and satisfaction with the recorded lectures exceeded that of real-time lectures across all grades (PM1: 2.90 versus 3.17; PM2: 2.56 versus 3.07; M1: 3.43 versus 3.66; M2: 2.41 versus 3.66). Medical students were significantly more satisfied with the curriculum than premedical students $(\mathrm{p}<0.001)$.

\section{Discussion}

The results of this study suggested that findings could be grouped divided into "educational phase-independent finding" and "educational phase-dependent finding".

In general, the relative ranking of items in one domain was found to be broadly similar among grades. First, students used "increasing playback speed" in nearly 70\% of the lectures. This finding is consistent with previous studies, which showed that students spent about $40 \%$ less time watching video feeds compared to those provided in the on-site live lectures format [6]. Instead, it seems that students used their spare time to take notes and search for material online. Second, our findings demonstrate that regardless of grades, the two most important elements in online classes are "good voice quality" and "use of virtual pointers". Maslow's hierarchy of needs, which states that one is motivated to pursue higherorder needs only when the lowest order of "physiological needs" are met [7], might be relevant to this finding. Unlike face-to-face lectures, in online settings, the transmission of quality audio and video becomes an additional prerequisite [8]; low quality lectures would significantly hinder learning. That is, in online classes, the immediate focus is on the satisfaction of lower-order needs, such as better audio and video quality. Only then can students seek higher-order needs, such as selfactualization and fulfillment, through the online curriculum.

Meanwhile, most of the items showed significant differences in responses between grades. These significant differences can be largely categorized into two types: first, those between premedical and medical students, and second, those between the PM1 and the other groups. The prominent characteristics of medical students, compared to premedical students, are: more daily studying hours; not viewing lectures simply for attendance checks; more active use of various learning strategies; and higher satisfaction with the curriculum. It has long been pointed out that premedical students often display problems related to unclear goals, poor identity as a medical student, and lowered motivation for learning. The current selection criteria of residency training programs, which only consider the GPA of the medical course, are assumed to be the principal cause [9]. Moreover, the demanding nature of the medical curriculum requires students to bear a significant 
workload. During the process, students usually adapt by aligning their behaviors with these external demands. In this regard, medical students' studying strategies and resource management behaviors are consistent with the characteristics that reportedly contribute to high academic achievement [10].

Some items were discerned only in PM1 students. First, they utilized various learning strategies lesser, on average, when compared to students in other grades, and it suggests that so-called millennial students' familiarity with technology does not necessarily guarantee its proficient use. Second, the students were less likely to make use of peer-to-peer collaboration while studying. The PM1 students might have struggled to form social relationships within the new environment of the medical school. The longer this situation prolongs, the more the probability of undeveloped collegiality negatively affecting PM1 students' professional development.

A limitation of our study is that our data were obtained from a single institution and investigated students' reaction but not actual knowledge acquisition. In conclusion, despite limitations, our study shows that premedical students, especially students who entered medical school during the COVID-19 pandemic, have different collective characteristics compared with their seniors while pre-clerkship students shared similar perceptions and behaviors in current situation. Future studies are needed to develop and implement educational strategies for PM1 students to support their learning as well as collegial interaction and socialization.

\section{ORCID:}

Ye Ji Kang: https://orcid.org/0000-0003-1711-2394;

Do-Hwan Kim: https://orcid.org/0000-0003-4137-7130

Acknowledgements: None.

Funding: None.
Conflicts of interest: No potential conflict of interest relevant to this article was reported.

Author contributions: DHK conceived the initial design of the study. YJK and DHK drafted the manuscript. DHK collected, analyzed, and interpreted the data. All authors read, critically reviewed, and approved the final manuscript.

\section{References}

1. Sit JW, Chung JW, Chow MC, Wong TK. Experiences of online learning: students' perspective. Nurse Educ Today. 2005;25(2):140-147.

2. Palloff RM, Pratt K. Lessons from the virtual classroom: the realities of online teaching. 2nd ed. Hoboken, USA: John Wiley \& Sons Inc.; 2013.

3. He L, Yang N, Xu L, et al. Synchronous distance education vs traditional education for health science students: a systematic review and meta-analysis. Med Educ. 2021;55(3):293-308.

4. Lee YM, Park KD, Seo JH. New paradigm of pediatric clinical clerkship during the epidemic of COVID-19. J Korean Med Sci. 2020;35(38):e344.

5. Choi B, Jegatheeswaran L, Minocha A, Alhilani M, Nakhoul M, Mutengesa E. The impact of the COVID-19 pandemic on final year medical students in the United Kingdom: a national survey. BMC Med Educ. 2020; 20(1):206.

6. Demetriadis S, Pombortsis A. E-lectures for flexible learning: a study on their learning efficiency. J Educ Technol Soc. 2007;10(2):147-157.

7. Kusurkar RA, Croiset G, Mann KV, Custers E, Ten Cate O. Have motivation theories guided the development and reform of medical education curricula?: a review of the literature. Acad Med. 2012;87(6):735-743.

8. Dong C, Goh PS. Twelve tips for the effective use of 
videos in medical education. Med Teach. 2015;37(2): 140-145.

9. Lee YM. It is time to reconsider the unnecessary division of premedical and medical studies. Korean J Med Educ. 2018;30(4):279-281.
10. Abdulghani HM, Al-Drees AA, Khalil MS, Ahmad F, Ponnamperuma GG, Amin Z. What factors determine academic achievement in high achieving undergraduate medical students?: a qualitative study. Med Teach. 2014;36 Suppl 1:S43-S48. 